\title{
L'ensenyament de la sintaxi atenent les intel-ligències múltiples
}

Margalida Ramon Sitjar (UIB)

ramon.margalida@gmail.com

\section{RESUM}

Partint del pressupòsit que cal atorgar un nou enfocament a l'ensenyament de la sintaxi dins l'ESO, aquest article proposa redefinir-ne l'estudi i aplicar-hi la teoria de les intel-ligències múltiples de Howard Gardner.

A més de presentar un marc teòric, oferim una seqüència didàctica per a l'assignatura de Llengua catalana adreçada a alumnes de quart d'ESO de les Illes Balears, amb la qual volem demostrar que és possible introduir canvis perquè l'ensenyament de la sintaxi vagi en consonància amb el nou enfocament comunicatiu que el currículum oficial estableix per a les assignatures de llengua i literatura, a través de la reflexió metalingüística.

PARAULES CLAU: sintaxi, reflexió metalingüística, intel-ligències múltiples, seqüència didàctica.

\section{ABSTRACT}

Operating from the assumption that there needs to be a new approach to the teaching of syntax within secondary education, this article aims to redefine its study and introduce the application of the Multiple Intelligences theory by Howard Gardner.

Along with a theoretical framework, we suggest a didactic sequence for the subject of Catalan language, addressed to fourth-year pupils of Compulsory

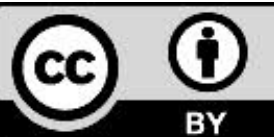


Secondary Education (ESO) in the Balearic Islands. With this, we intend to demonstrate the plausibility of making adjustments to the current teaching of syntax through metalinguistic awareness that goes hand-in-hand with the new communicative approach (CLT) established in the language and literature national curriculum.

KEY WORDS: syntax, metalinguistic awareness, multiple intelligences, didactic sequence.

\title{
ÍNDEX
}

\author{
1. Consideracions prèvies \\ 2. Marc teòric \\ 3. Desenvolupament de la proposta \\ 4. Conclusions \\ 5. Bibliografia
}

\section{Consideracions prèvies}

Cal ensenyar gramàtica a l'educació secundària obligatòria si el currículum actual adopta un enfocament comunicatiu? A finals del segle passat, com expliquen Cassany, Luna i Sanz (2009: 83), començà a desenvolupar-se «una visió funcionalista i comunicativa de la llengua, que ha revolucionat tant la investigació, com també l'ensenyament i l'aprenentatge dels idiomes», i que s'ha reflectit en les lleis que regulen l'educació.

Anys enrere el centre d'atenció de les matèries lingüístiques era l'ensenyament de la gramàtica, entès com la interiorització d'uns continguts conceptuals sobre ortografia, morfosintaxi, fonètica i lèxic, però es deixava de banda l'estudi de la relació que s'estableix entre gramàtica i ús durant els actes comunicatius. Avui en dia, però, s'ha demostrat que en l'aprenentatge de les llengües cal prestar atenció a la comunicació, que ha passat a ser el vertader objectiu de les assignatures de llengua. És per aquest motiu que ens plantegem si en aquest context encara té algun sentit seguir ensenyant gramàtica. Des del nostre punt de vista la resposta és afirmativa i intentarem demostrar-ne la seva utilitat. Entenem que en acabar l'assignatura de Llengua catalana els alumnes haurien de saber comunicar-se, però creiem que això només s'aconseguirà si es treballen conjuntament destreses 
comunicatives i gramàtica. Partint del model de les Seqüències didàctiques per aprendre gramàtica (Camps i Zayas, 2006) aportarem un nou punt de vista, ja que introduirem la teoria de les intel-ligències múltiples, teoritzada per Howard Gardner, per aconseguir que tots els alumnes siguin atesos amb igualtat de condicions.

\section{Marc teòric}

\subsection{L'ensenyament de la gramàtica}

En els darrers temps s'han sentit algunes veus que rebutgen l'estudi de la gramàtica, argumentant que no és necessari per desenvolupar les habilitats lingüístiques. Per contra, però, molts estudiosos han reafirmat la seva utilitat. De fet, han sorgit diferents iniciatives encapçalades per professors universitaris i de secundària que proposen treballar la gramàtica des d'un nou punt de vista, com és el cas del grup GrOc (Gramàtica orientada a les competències), que dirigeix aquesta mateixa revista. Com bé expliquen Bosque i Gallego (en premsa: 6), no es rebutja que els alumnes hagin d'aprendre a llegir o a escriure: «estamos totalmente de acuerdo en que los estudiantes deben saber redactar con soltura, dominar los matices del léxico, construir textos bien articulados, etc.», sinó que van un pas més enllà i reclamen que aquest aprenentatge de les habilitats comunicatives vagi acompanyat dels aspectes més científics de la llengua: «lo que nos resulta extraño es que ese conocimiento no vaya acompasado con cierta información sobre la estructura que subyace a ese "uso"». Actualment sembla que basta treballar la llengua d'una manera superficial, quan això seria impensable per a les assignatures de ciències. Demanen, així doncs, el mateix paper per a les assignatures lingüístiques, i és en aquest sentit que hem desenvolupat la nostra proposta didàctica.

\subsection{La reflexió metalingüística}

Segons el currículum de l'assignatura de Llengua catalana i literatura, «la finalitat de la matèria és la reflexió -que s'ha iniciat a primària i que és, per tant, progressiva- en dos sentits, lingüístic i literari» (Decret de currículum: 25284). Aquesta pràctica, però, sovint és deixada de banda, quan realment hauria de ser la més treballada a l'hora de tractar la gramàtica. El model cap al qual tants 
estudiosos afirmen que s'ha d'encaminar l'educació gramatical és, precisament, la reflexió metalingüística, aquella activitat en què es reflexiona sobre la llengua a través de la mateixa llengua, de manera que «el llenguatge és alhora objecte de coneixement i instrument per a la seva construcció» (Camps, 2000: 104).

Els motius que s'al-ludeixen a favor d'aquesta activitat són els següents. En primer lloc, resoldria la crítica que es dirigeix contra l'ensenyament gramatical: la poca relació que s'estableix entre allò que s'explica i el coneixement implícit que posseeix l'alumne. A través de la reflexió metalingüística es faria explícit allò que l'alumne ja sap de manera intuïtiva. En segon lloc, dotaria l'alumne de les eines necessàries per saber elegir l'opció adequada a l'hora de comunicar-se i per avaluar-se. En tercer lloc, contribueix a fomentar la consciència lingüística i a fer entendre als alumnes que la competència comunicativa és un tot indissoluble, la qual cosa hauria de desencadenar una millora de les seves habilitats lingüístiques. Finalment, promou «una actitud d'indagació, curiositat, qüestionament davant la llengua» (Camps, Guasch, Milian i Ribas, 2005: 163), i és que entenem que l'educació també ha de promoure l'adquisició d'actituds i valors que aconsegueixin la formació integral dels estudiants.

\subsection{Les intel-ligències múltiples}

La teoria de les intel-ligències múltiples fou batejada per Howard Gardner el 1983 a l'obra Frames of Mind: The Theory of Multiple Intelligences i a partir d'aleshores s'introduí una concepció de la intel-ligència humana que revolucionaria els camps de la psicologia i l'educació. Proposà l'existència de vuit tipus d'intel-ligències que tota persona posseeix i té desenvolupades en major o menor mesura: intel-ligència lingüística, musical, logicomatemàtica, espacial, corporal-cinestèstica, interpersonal, intrapersonal i naturalista.

Els treballs $\mathrm{i}$ articles actuals que proposen aplicar aquesta teoria a l'ensenyament de la llengua recomanen diferents tipus d'activitats per desenvolupar cada intel-ligència, com per exemple dur a terme activitats de lectura, escriptura, parla o audició per treballar la intel-ligència lingüística; usar la metodologia inductiva per a la logicomatemàtica; i fer activitats amb moviment, jocs de rols o vídeos per a la corporal-cinestèsica, però no s'ofereix material didàctic concret per treballar el contingut que estableix el currículum. 


\subsection{Les seqüències didàctiques}

La proposta metodològica de les seqüències didàctiques (SD), sorgida en el Grup de Recerca sobre l'Ensenyament i Aprenentatge de Llengües (GREAL) de la Universitat Autònoma de Barcelona, és el patró que seguim per desenvolupar la nostra unitat didàctica.

Les SD, igual que l'aprenentatge basat en problemes o en projectes (ABP), s'organitzen a partir de diferents tasques que persegueixen un objectiu global que els vertebra: «parteixen d'una pregunta -d'una problematització sobre el sistema de la llengua, d'una curiositat lingüística que es vol indagar- que caldrà que sigui interessant i significativa per als alumnes» (Camps et al., 2005: 160).

Una seqüència didàctica per aprendre gramàtica (SDG) es divideix en tres fases (Camps, 2006: 33). A la primera, "definició de la tasca», s'ha de determinar un objectiu, que serà allò que vehicularà la seqüència, i s'avancen quins són els coneixements gramaticals que es treballaran. Aquesta fase inicial acaba amb l'establiment del problema. La segona és el «desenvolupament de la tasca», en què es duen a terme diferents activitats per resoldre el problema establert a la primera etapa. La SDG acaba amb un «informe i avaluació». Els alumnes han de reflexionar sobre la feina que han realitzat i l'han de reflectir en un informe.

\section{Desenvolupament de la proposta}

A continuació, presentem una seqüència didàctica per treballar la sintaxi, introduint la reflexió metalingüística i la teoria de les intel-ligències múltiples. Concretament ens centrarem en l'estudi de dos complements verbals i dels pronoms febles de tercera persona que els substitueixen: és el cas del complement directe $\mathrm{i}$ indirecte, $\mathrm{i}$ els pronoms febles d'acusatiu i datiu. Així mateix, perquè l'aplicació de la teoria de les intel-ligències múltiples sigui realment profitosa $\mathrm{i}$ significativa, hem decidit que en aquesta SD se'n treballin cinc (la lingüística, la logicomatemàtica, l'espacial, la interpersonal i la intrapersonal). Pretenem que els nostres alumnes, mitjançant un treball de camp, ${ }^{1}$ investiguin sobre sintaxi, reflexionin explícitament sobre la llengua, i emetin un informe escrit i un vídeo

\footnotetext{
${ }^{1}$ Som conscients que la pràctica que es durà a terme és una observació preexperimental, que es troba allunyada d'un vertader estudi de camp, però considerem que és útil perquè s'hi familiariaritzin mínimament.
} 
sobre la investigació realitzada. En cap cas, tampoc no oblidarem el treball de les habilitats lingüístiques.

\subsection{Introducció i justificació}

La seqüència didàctica que oferirem tot seguit porta per títol Ens convertim en lingüistes: un treball de camp sobre els pronoms febles d'acusatiu $i$ datiu. D’aquesta manera convidem els alumnes a assumir un nou rol i experimentar, per uns dies, en què consisteix la feina que duen a terme els experts en llengua. $\mathrm{A}$ més, introduïm la noció del treball de camp, que probablement no han realitzat mai durant la seva etapa formativa. Aquesta nova manera d'estudiar la sintaxi pot semblar atractiva als alumnes, «perquè passen de respondre preguntes i resoldre exercicis gramaticals, a formular preguntes i fer activitats per analitzar què se sap sobre la llengua» (Camps i Zayas, 2006: 13). Pel que fa al nivell educatiu, està pensada per a quart d'ESO, un curs decisiu -l'últim de l'etapa obligatòria-, en què els alumnes, de 15 i 16 anys, ja han adquirit les bases per iniciar-se com a petits investigadors. Consta de vuit sessions i es podria desenvolupar en qualsevol moment del curs.

\subsection{Objectius didàctics i competències clau}

A la següent taula recollim els objectius didàctics que els alumnes haurien d'haver assolit en acabar la seqüència didàctica. Del primer al sisè els hem estructurat seguint la Taxonomia de Bloom (López, 2014), és a dir, establint les habilitats cognitives de menor a major complexitat (recordar, comprendre, aplicar, analitzar, avaluar i crear). Els setè, vuitè i novè són objectius més generals, que no només es treballaran en aquesta unitat didàctica, sinó que s'aniran adquirint al llarg del curs. Finalment, els desè i onzè es relacionen amb les actituds que els alumnes han de desenvolupar envers la llengua. A més, hem relacionat cada objectiu amb les competències clau que desenvolupa.

\begin{tabular}{|l|l|}
\hline Objectius didàctics & Competències clau \\
\hline $\begin{array}{l}\text { 1. Identificar les funcions sintàctiques de complement } \\
\text { directe i indirecte }\end{array}$ & Comunicació lingüística \\
\hline $\begin{array}{l}\text { 2. Sintetitzar la informació que ofereixen les obres de } \\
\text { referència gramaticals sobre les funcions sintàctiques }\end{array}$ & Comunicació lingüística \\
\cline { 2 - 2 } i la substitució pronominal & Aprendre a aprendre \\
\cline { 2 - 2 } & Competència digital \\
\hline
\end{tabular}




\begin{tabular}{|c|c|}
\hline \multirow[t]{2}{*}{ 3. Preparar qüestionaris d'elicitació } & Comunicació lingüística \\
\hline & Sentit d'iniciativa i esperit emprenedor \\
\hline \multirow{2}{*}{$\begin{array}{l}\text { 4. Estructurar les dades obtingudes a través dels } \\
\text { qüestionaris d'elicitació }\end{array}$} & Comunicació lingüística \\
\hline & Aprendre a aprendre \\
\hline \multirow{3}{*}{$\begin{array}{l}\text { 5. Comparar les similituds i diferències entre la } \\
\text { normativa i l'ús real del sistema pronominal } \\
\text { d'acusatiu i datiu }\end{array}$} & Comunicació lingüística \\
\hline & Competències socials i cíviques \\
\hline & Sentit d'iniciativa i esperit emprenedor \\
\hline \multirow{3}{*}{$\begin{array}{l}\text { 6. Elaborar un informe i un vídeo amb els resultats } \\
\text { que s'han obtingut del treball de camp }\end{array}$} & Comunicació lingüística \\
\hline & Competència digital \\
\hline & Sentit d'iniciativa i esperit emprenedor \\
\hline \multirow{2}{*}{$\begin{array}{l}\text { 7. Expressar-se amb correcció tant oralment com per } \\
\text { escrit }\end{array}$} & Comunicació lingüística \\
\hline & Competències socials i cíviques \\
\hline \multirow{2}{*}{$\begin{array}{l}\text { 8. Interpretar els discursos orals i escrits de l'àmbit } \\
\text { acadèmic i social }\end{array}$} & Comunicació lingüística \\
\hline & Competències socials i cíviques \\
\hline \multirow{2}{*}{$\begin{array}{l}\text { 9. Utilitzar autònomament i amb esperit crític les } \\
\text { tecnologies de la informació per obtenir i presentar } \\
\text { informació }\end{array}$} & Comunicació lingüística \\
\hline & Competència digital \\
\hline \multirow{2}{*}{$\begin{array}{l}\text { 10. Valorar la llengua com a mitjà de comunicació } \\
\text { necessari per inserir-se dins la societat }\end{array}$} & Comunicació lingüística \\
\hline & Competències socials i cíviques \\
\hline 11. Apreciar la variació lingüística com una riquesa & Competències socials i cíviques \\
\hline
\end{tabular}

Taula 1. Relació entre objectius didàctics i competències clau

\subsection{Metodologia i atenció a la diversitat}

Com que les seqüències didàctiques estan dissenyades com un petit projecte que es clou amb la consecució de la tasca final, podem dir que la principal metodologia utilitzada és la d'aprenentatge basat en problemes (ABP). Així doncs,

primer es presenta el problema, i a partir de la delimitació d'allò que ja es coneix i d'allò que no se sap, s'estableixen els objectius, s'identifiquen les necessitats d'aprenentatge que són bàsiques, es dissenya i se segueix un pla d'actuació, perquè al llarg del procés en què es produeix l'aprenentatge, es resolgui simultàniament el problema. (Grau, 2006)

Partint d'unes preguntes inicials (el problema), arribarem a la conclusió que, per donar-los resposta, s'ha de realitzar un petit projecte. D’aquesta manera els estudiants arribaran a aprendre gramàtica investigant, atès que hauran d'analitzar què diuen les gramàtiques normatives, fer hipòtesis i elaborar qüestionaris d'elicitació, per després sortir al carrer i recollir mostres de parlants reals, gent del seu entorn. Per tant, extrapolaran els continguts apresos a classe 
al món real i s'adonaran de la seva utilitat. Finalment hauran d'examinar les dades i comparar l'ús normatiu dels pronoms febles amb l'ús real. Les conclusions, que haurien de resoldre el problema plantejat a la primera sessió, s'hauran de redactar com un informe i també s'hauran d'exposar en un vídeo. Amb tot, doncs, pretenem aconseguir dues activitats (Camps i Fontich, 2006: 100): una de recerca -a través del treball de camp-i una d'aprenentatge, a partir dels continguts gramaticals treballats, que seran utilitzats per millorar la competència en comunicació lingüística.

Per arribar a tot l'alumnat, incorporar les intel-ligències múltiples i, per tant, atendre la diversitat d'una manera inclusiva, interrelacionarem diferents metodologies. D'aquesta manera, seguirem els tres principis que presenta el disseny universal d'aprenentatge (DUA): oferirem als alumnes múltiples formes de representació (a través de les diferents metodologies i intel-ligències desenvolupades), expressió (mitjançant l’informe i el vídeo lliure) i implicació (a través d'activitats motivadores, com el Kahoot o el treball de camp). Així doncs, a part de l'ABP, que és la metodologia que vertebra la seqüència didàctica, n'utilitzarem d'altres com la inducció guiada, el treball cooperatiu, l'aprenentatge individual, l'ús de les TIC, la classe inversa, la ludificació i el visual thinking.

La inducció guiada entrarà en joc en el desenvolupament de les activitats que s'aniran duent a terme per aconseguir la tasca final. Es tracta d'una metodologia que possibilita la reflexió metalingüística i que inverteix els papers respecte al model expositiu i magistral tradicional: el docent subministra uns exemples específics perquè els estudiants, per ells mateixos, arribin a formular conclusions a través d'inferències. Aquest, de fet, és el mètode que s'utilitza en qualsevol disciplina científica, atès que s'estableixen generalitzacions a partir de la comparació entre casos particulars.

Així mateix, posarem en pràctica el treball cooperatiu en grups heterogenis a gairebé totes les sessions. A part de propiciar la reflexió metalingüística i d'afavorir la intel-ligència interpersonal, fomentarem la participació de tots els alumnes, ja que cada un tindrà unes responsabilitats, de manera que la seva feina i col-laboració seran peces essencials per obtenir uns bons resultats. Aquesta metodologia també ens ajudarà a atendre la diversitat d'una manera inclusiva: els 
estudiants que puguin tenir algun tipus de necessitat específica estaran integrats en grups iguals als dels seus companys i no els etiquetarem ni estigmatitzarem com a ANESE (alumnes amb necessitats específiques de suport educatiu). Tot i això, en algunes sessions també es treballarà l'aprenentatge individual, ja que considerem profitós que els alumnes, en algun moment, treballin sols per veure com es desenvolupen individualment i per poder reflexionar sobre el seu aprenentatge personal. Els alumnes amb intel-ligència intrapersonal veuran reforçada la seva capacitat a través d'aquesta metodologia de treball.

La classe inversa (flipped classroom) serà una altra metodologia posada en pràctica, que pot ajudar a desenvolupar, entre d'altres, la intel-ligència espacial. El professor ofereix una informació (vídeos, pàgines web, recursos) que els alumnes han de consultar a casa per després dur a terme la pràctica a les aules. S'ha demostrat que aquesta metodologia augmenta la motivació dels alumnes, s'adapta als diferents ritmes d'aprenentatge, ofereix major temps al docent per dedicar-se als alumnes, propicia la participació de les famílies i fomenta l'ús de les TIC, entre d'altres.

Finalment, les dues últimes metodologies de treball que farem servir seran la ludificació (o gamificació) -en una sessió introduirem el Kahoot- i el visual thinking, que serà la porta d'accés als continguts per a aquells alumnes que tenen més desenvolupada la intel-ligència espacial. Aquesta es fomentarà en el vídeo de classe inversa, en l'elaboració de les taules en què s'organitzaran les dades i en el vídeo que hauran de realitzar per penjar a YouTube.

\subsection{Seqüenciació d'activitats}

Les activitats que es duran a terme al llarg de les diferents sessions responen a un objectiu comú, que és assolir la tasca final: l'elaboració d'un informe i la gravació d'un vídeo amb les conclusions extretes. Presentem les activitats en una taula, seguint les tres grans fases de les SDG, i també les descrivim sessió per sessió. 


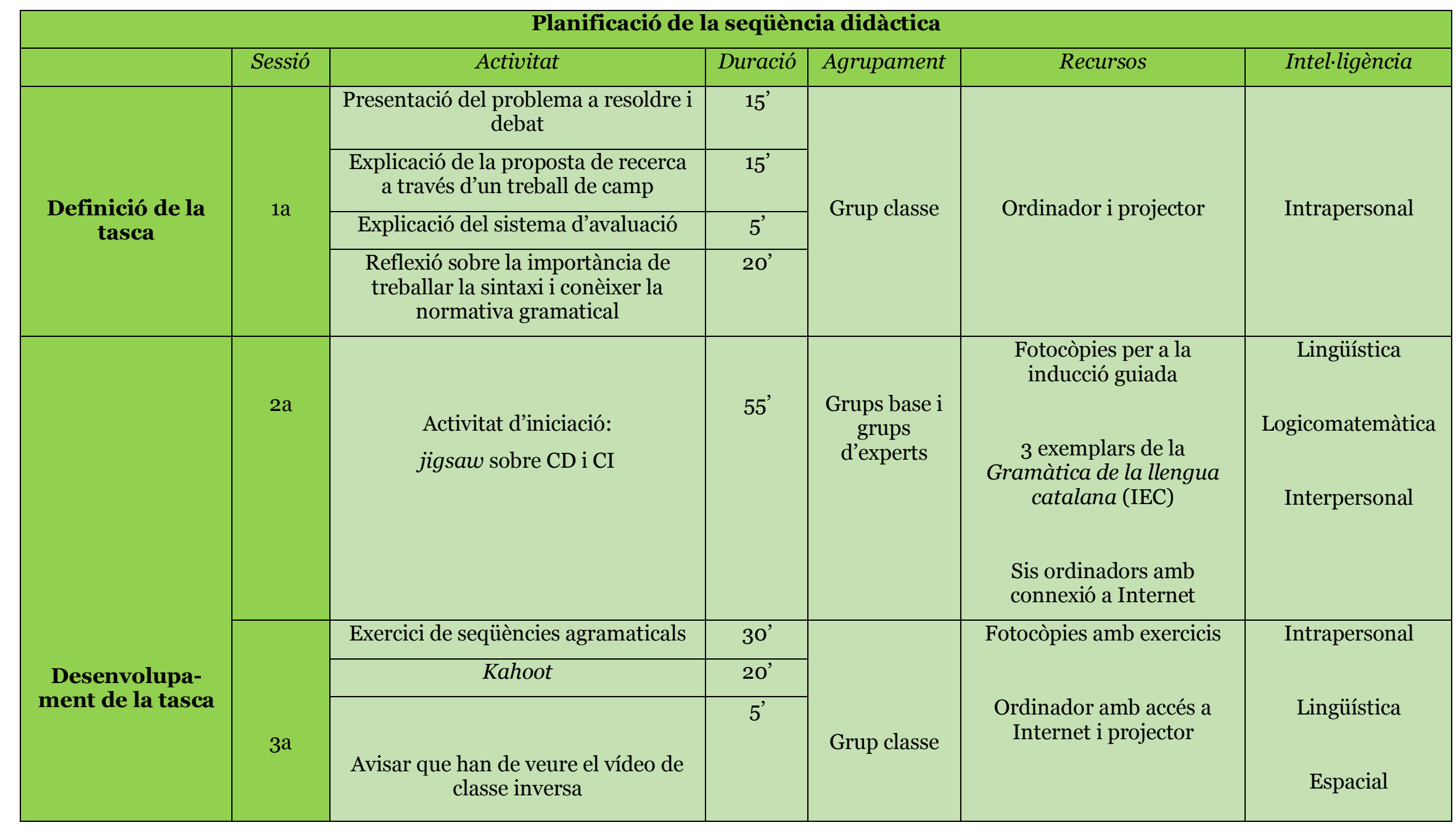




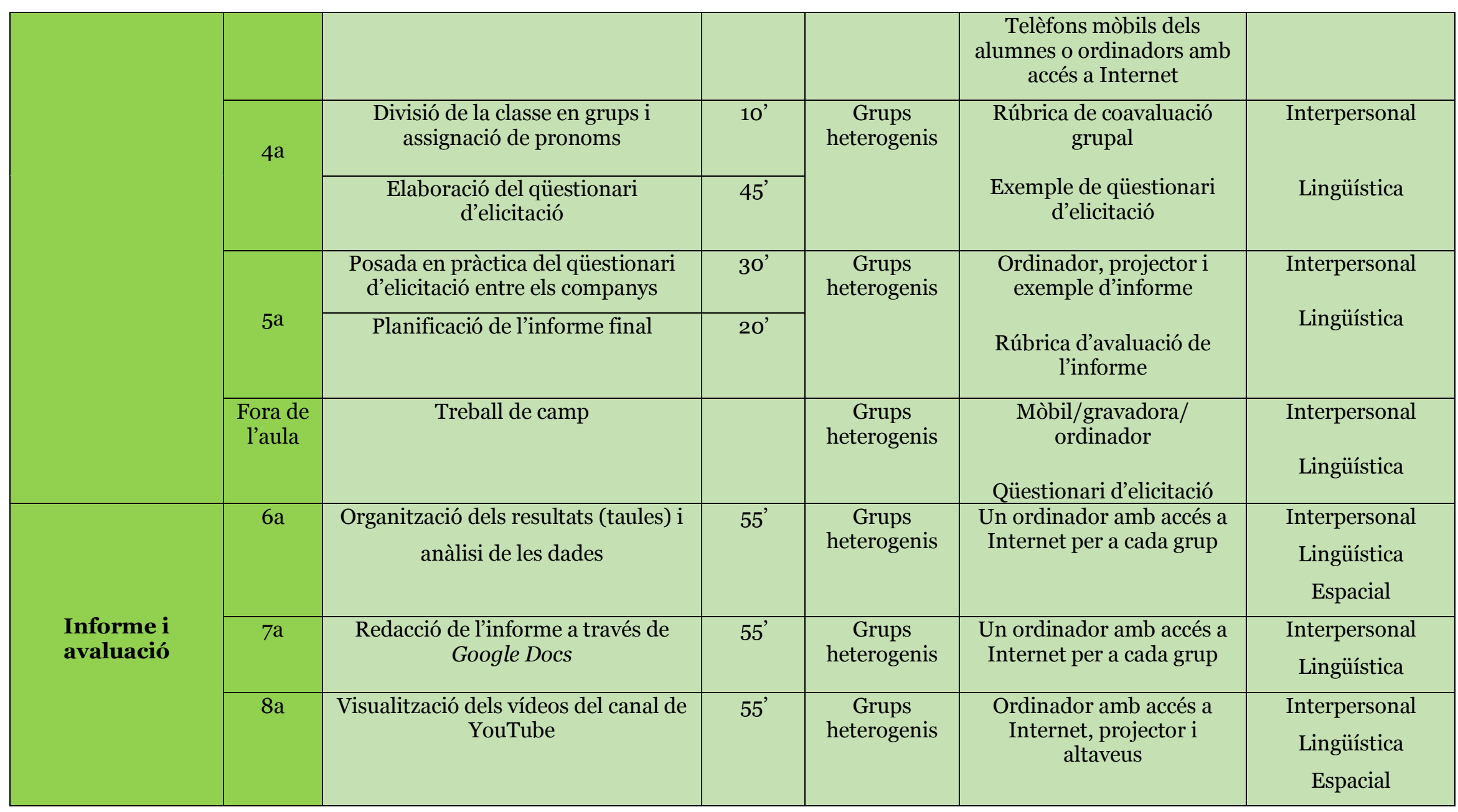

Taula 2. Planificació de la seqüència didàctica 


\section{Primera sessió}

A la primera sessió es durà a terme la primera fase de les SDG, és a dir, la definició de la tasca, que és la curiositat lingüística que es vol indagar: l'eix que vertebra la seqüència. Els plantejarem un problema i les preguntes que encaminaran el debat seran del tipus: «utilitzeu el pronom feble lis quan parleu o escriviu?», «sabeu si aquesta forma és normativament correcta? Per què? Quin seria el pronom feble equivalent normatiu?», «i les combinacions els el, la hi, els els..., les dieu?», «i els vostres amics, pares i padrins? Com podem descobrir-ho?». Probablement la resposta a aquesta última pregunta sigui enquestant-los, que serà, precisament, la tasca que hauran de realitzar: han de descobrir com emeten els pronoms d'acusatiu i datiu la gent del seu voltant. Per això, els explicarem en què consisteix el treball de camp, què són els qüestionaris d'elicitació, els informants i quins seran els pronoms febles sobre els quals hauran de realitzar la investigació. Per tant, anticipem la tasca que han d'acabar resolent, allò que s'ha d'aprendre, i elaborem el problema a partir dels coneixements dels alumnes. Creiem que és fonamental que, en tot moment, tinguin present què esperem d'ells, per la qual cosa, ja a la primera sessió, els explicarem com se'ls avaluarà: a partir d'uns exercicis que faran a la tercera sessió, l’informe final, la coavaluació grupal i el vídeo que hauran de penjar a YouTube.

Així mateix, els avisarem que per a la tercera sessió han de portar un telèfon mòbil amb connexió a Internet, ja que el necessitarem per realitzar un Kahoot. Finalment, la darrera activitat que farem serà de reflexió. Pretenem que el punt de partida de la proposta didàctica sigui el més proper possible a l'alumnat perquè la tasca a desenvolupar sigui un aprenentatge significatiu real. Camps et al. (2005: 160) ja alerten sobre aquest fet: «caldrà vetllar perquè les situacions que es creïn per iniciar la seqüència impliquin els alumnes». Per la naturalesa de la tasca final, creiem que la SDG esdevindrà una proposta que s'integrarà completament dins el seu entorn, que els implicarà afectivament -ja que hauran d'enquestar persones properes- i que es relacionarà amb els coneixements que han assolit prèviament en els cursos anteriors i que formen part de la seva estructura cognitiva. No obstant això, per justificar encara més la importància de treballar la sintaxi i conèixer la normativa, els projectarem textos reals de diferents procedències, seguint la recomanació de Jimeno (2017: 30), segons la qual «recórrer a textos reals, complets o fragmentaris és la millor manera 
d'aconseguir que la reflexió sigui percebuda com quelcom proper i útil». El nostre objectiu és que s'adonin de la necessitat de saber gramàtica per escriure amb adequació, coherència, cohesió i correcció, i que l'escriptura (igual que l'oralitat) és la manera que tenim de comunicar-nos, de presentar-nos al món. Així doncs, els projectarem textos seus o escrits per alumnes de la seva mateixa edat perquè s'adonin de les errades que cometen, i que es poden corregir sabent sintaxi. Amb aquesta activitat, doncs, estarem reforçant la intel-ligència intrapersonal, atès que farem reflexionar l'alumne sobre si mateix perquè arribi a la conclusió que ha de seguir mantenint o que ha de canviar la seva actitud i/o accions respecte a la sintaxi i la comunicació. El coneixement d'un mateix, de les fortaleses i de mancances és la primera passa per poder millorar en qualsevol àmbit.

\section{Segona sessió}

Un cop definida la tasca, començarem amb una activitat d'iniciació perquè els alumnes esdevinguin conscients del seu coneixement sobre sintaxi i el sistema pronominal. D'aquesta manera, s'adonaran d'allò que saben i d'allò que desconeixen, uns aprenentatges que necessàriament hauran d'adquirir per dur a terme la tasca final que se'ls ha assignat.

Es tracta d'una dinàmica d'aprenentatge cooperatiu anomenada trencaclosques o jigsaw, que consta de tres fases. A la primera formarem grups base heterogenis de tres persones, a cadascuna de les quals assignarem un rol. El rol A correspon a «Expert en complement directe i pronoms febles d'acusatiu»; el rol B, a «Expert en complement indirecte i pronoms febles de datiu», i el rol C, a «Expert en combinació dels pronoms febles d'acusatiu i datiu». Un cop assignats els papers, indicarem que s'ajuntin, en grups d'experts (homogenis), tots els que tinguin el rol A, el B i el C. Aleshores, dividits ja en grups d'experts, cada equip, a partir d'uns exercicis d'inducció guiada -que podeu trobar, a tall d'exemple, a la taula 3- han d'arribar a respondre qüestions sobre el tipus de sintagma que formen els complements directe $\mathrm{i}$ indirecte, com es poden reconèixer, com es pronominalitzen de manera simple i combinats, etc. Quan ja hagin resolt aquestes preguntes, els proporcionarem dos ordinadors per grup perquè consultin la Gramàtica catalana de Pompeu Fabra, que es troba en línia, i un exemplar per equip de la nova Gramàtica de la llengua catalana, perquè puguin comparar què en diuen al respecte i quines semblances i diferències hi ha amb el 
que havien escrit ells. Aquesta pràctica, a més, els ajudarà a ser més autònoms com a aprenents i a familiaritzar-se amb obres de referència, atès que sovint el coneixement els ve donat fragmentat en els llibres de text, i gairebé mai no s'enfronten a la consulta d'obres completes.

Preguntes per al rol A: Expert en complement directe i pronoms febles d'acusatiu 1- Sabríeu dir quins tipus de sintagmes poden fer de complement directe?

2- Com es poden reconèixer els complements directes?

Oracions (titulars periodístics) per a la inducció

1. Els nets i besnets dels patriarques Tejedor han inventat terrines i talls de sobrassada empaquetats $\rightarrow$ terrines i talls de sobrassada empaquetats han estat inventats pels nets i besnets dels patriarques Tejedor

2. La Plataforma per la Llengua posarà sobre un mapa els comerços que no atenen en català $\rightarrow$ els comerços que no atenen en català seran posats sobre un mapa per la Plataforma per la Llengua

3. Els clients dels comerços podran valorar l'ortografia o la fonètica del personal? $\rightarrow$ l'ortografia o la fonètica del personal podran ser valorades pels clients dels comerços?

4. Les noies infravaloren i els nois sobrevaloren les seves capacitats en tecnologia $\mathbf{i}$ matemàtiques $\rightarrow$ les seves capacitats en tecnologia i matemàtiques són infravalorades per les noies i sobrevalorades pels nois

Taula 3. Exercicis d'inducció guiada ${ }^{2}$

Finalment, tots els alumnes han de tornar al grup base $\mathrm{i}$ han d'explicar als altres dos companys (que tenien un rol diferent i que, per tant, desconeixen encara aquell tema) les conclusions a què han arribat en el grup d'experts de què formaven part, i tots n'han de prendre nota. Al final, tothom tindrà la mateixa informació gràcies a la feina dels companys i de la seva pròpia.

En aquesta sessió es posaran en pràctica diferents tipus d’intel-ligències: la lingüística, que també es desenvoluparà a la resta de sessions, atès que l'objecte d'estudi és el sistema lingüístic i es posen en pràctica totes les habilitats lingüístiques; la logicomatemàtica a partir dels exercicis d’inducció guiada; i la interpersonal gràcies al trencaclosques.

\footnotetext{
${ }^{2}$ En aquesta taula únicament presentem alguns exemples perquè el lector pugui fer-se una idea de què són els exercicis d'inducció guiada. Els alumnes, per respondre la primera pregunta, haurien de localitzar tots els exemples de CD i determinar quins tipus de sintagmes funcionen com a tals. Per a la segona, s'haurien d'adonar que una manera de reconèixer el CD és passar l'oració a passiva (els complements directes esdevenen subjectes pacients). També s'haurien de proporcionar exemples perquè dedueixin com es realitza la substitució pronominal.
} 


\section{Tercera sessió}

Abans de començar a preparar els qüestionaris que hauran de passar als informants, volem certificar que han assumit els coneixements tractats a la sessió anterior, ja que són fonamentals perquè sàpiguen crear les enquestes. Per aquest motiu, dedicarem aquesta sessió a realitzar dues activitats. La primera consistirà en l'anàlisi de seqüències agramaticals a partir del model d'exercicis proposats per Bosque i Gallego (2016: 77). Els recursos plantejats per aquests dos autors defugen les pràctiques habituals $i$ es proposen desenvolupar la capacitat de reflexió dels estudiants sobre les estructures gramaticals. Nosaltres posarem en pràctica un tipus d'exercicis en què els alumnes hauran d'exposar per quin motiu les seqüències proposades no són gramaticals. Els autors ja avisen que aquest tipus d'activitats són complexes, però cal que anem una passa més enllà, perquè els estudiants reflexionin metalingüísticament i ordenin els seus coneixements sobre sintaxi a l'hora de posar-los per escrit.

A continuació, durem a terme un Kahoot, 3 és a dir, un qüestionari amb preguntes d'opció múltiple sobre anàlisi sintàctica i pronominalització. Els alumnes es van situant en un rànquing, en què poden canviar de posició segons la rapidesa i l'encert de les seves respostes. Abans de començar els avisarem que els tres primers classificats obtindran una bonificació a la nota final d'aquesta seqüència didàctica. D’aquesta manera, pretenem motivar-los més i sorprendre'ls introduint el telèfon mòbil com a recurs didàctic (Olmos, 2017).

Finalment, els explicarem que, per a la propera sessió, han de visualitzar un vídeo de classe inversa en què els donarem les pautes per poder començar a fer feina a la propera sessió: establirem el nombre de persones per grup, les formes a enquestar, el nombre d’informants, el format que han de tenir els qüestionaris d'elicitació, com han d'entrevistar els enquestats, etc.

\section{Quarta sessió}

Pressuposant que han vist el vídeo de classe inversa, assignarem un objecte d'anàlisi diferent a cada grup. A partir d'aquesta sessió i fins al final de la unitat didàctica, els alumnes hauran de treballar en grup amb els seus companys, de manera que una de les intel-ligències que més es desenvoluparà durant aquestes

\footnotetext{
${ }^{3}$ Podeu consultar el Kahoot que hem dissenyat en el següent enllaç: https://play.kahoot.it/\#/k/ood670ae8273-4e89-93do-43b34f3f29f5
} 
sessions serà la interpersonal, així com les competències socials i cíviques que hi van estretament lligades. Per això, és important que avaluïn els seus companys a través d'una rúbrica de coavaluació grupal. Imaginant que tenim una classe de 28 alumnes, formaríem set equips de quatre persones:

\begin{tabular}{|l|l|}
\hline Grup 1 & $\begin{array}{l}\text { Pronoms febles que substitueixen el complement directe determinat singular (el, } \\
\text { la) avantposats al verb i posposats }\end{array}$ \\
\hline Grup 2 & $\begin{array}{l}\text { Pronoms febles que substitueixen el complement directe determinat plural (els, } \\
\text { les) avantposats al verb i posposats }\end{array}$ \\
\hline Grup 3 & $\begin{array}{l}\text { Pronoms febles que substitueixen el complement directe indeterminat i neutre } \\
\text { (en, ho) avantposats al verb i posposats }\end{array}$ \\
\hline Grup 4 & $\begin{array}{l}\text { Pronoms febles que substitueixen el complement indirecte singular masculí i } \\
\text { femení, i plural masculí i femení (li, els) }\end{array}$ \\
\hline Grup 5 & $\begin{array}{l}\text { Combinació del pronom feble } l i \text { (3a persona singular datiu) amb el, la, els, les } \\
\text { (3a persona singular i plural acusatiu) }\end{array}$ \\
\hline Grup 6 & $\begin{array}{l}\text { Combinació del pronom feble } \text { els (3a persona plural datiu) amb el, la, els, les (3a } \\
\text { persona singular i plural acusatiu) }\end{array}$ \\
\hline Grup 7 & $\begin{array}{l}\text { Combinació dels pronoms febles } l i \text { i els (3a persona singular i plural datiu) amb } \\
\text { en (CD indeterminat) i ho (CD neutre) }\end{array}$ \\
\hline
\end{tabular}

En tots els casos, els grups hauran d'esbrinar com es realitzen quatre produccions. Un cop assignats els objectes d'estudi a cada grup, dedicarem la resta de la sessió a elaborar els qüestionaris per recollir les dades. S’hauran de dissenyar amb dues possibilitats d'elicitació, per si de cas amb una de les dues no s'obtenen els resultats esperats. La primera és la compleció de frases: els alumnes hauran d'elaborar oracions amb el buit a omplir que equivalgui a la construcció que enquesten. La segona serà la traducció del castellà al català: hauran d'inventar oracions en castellà, en la traducció catalana de les quals apareguin els pronoms febles requerits, perquè l'informant les tradueixi i les emeti tal com les diria habitualment. Abans de començar amb l'elaboració, els ensenyarem alguns qüestionaris de mostra, perquè entenguin què han de fer exactament.

\section{Cinquena sessió}

La primera mitja hora posarem en pràctica els qüestionaris, és a dir, els diferents grups s'enquestaran entre ells, per veure si les proves que han elaborat funcionen. A més, aquesta pràctica els servirà per veure com han d'actuar el dia que 
enquestin els informants reals. Els darrers vint minuts de la sessió es dedicaran a la planificació de l'informe final. Primer els presentarem l'exemple d'un informe, perquè es formulin una idea del que han de fer, i després, entre tots, veurem quines parts i característiques presenta aquest text. Posteriorment els facilitarem unes pautes d'elaboració i una rúbrica amb els ítems en què s'hauran de fixar i que haurà de contenir l'informe.

\section{Sisena sessió}

Entre la sessió anterior i aquesta deixarem que passi almenys una setmana, perquè els alumnes hagin tingut temps de recollir les dades. Així doncs, assegurant-nos que tots els grups han realitzat les enquestes, els alumnes han de procedir a organitzar els resultats obtinguts en taules. Això pot ajudar els estudiants amb intel-ligència espacial a visualitzar millor la informació obtinguda. Tot seguit, s'hauran de comparar les dades reals amb el que estableix la normativa, i se n'haurà de fer una anàlisi crítica tenint en compte la diversitat diastràtica, diacrònica i dialectal, que després els servirà per incloure a l’informe. Entenem que aquesta és una tasca complexa, per a la qual hauran de posar en pràctica tots els mecanismes de reflexió metalingüística que posseeixin. I és que, de fet, aquest serà un dels moments centrals en què es desenvoluparà l'objectiu que volem aconseguir: que els alumnes reflexionin sobre la llengua i n'entenguin el seu funcionament.

\section{Setena sessió}

Dedicarem la sessió a la redacció de l'informe. Aquesta última tasca s'entén que és el punt de confluència entre les dades obtingudes a partir de la recerca i els aprenentatges adquirits durant les sessions, atès que per posar per escrit la informació de les enquestes, s'han de mobilitzar tota una sèrie de coneixements gramaticals, que són els que pretenem que hagin assolit amb aquesta seqüència didàctica. El text s'elaborarà a través de Google Docs perquè el professor pugui anar veient i corregint simultàniament la feina que estan fent els grups.

\section{Vuitena sessió}

Per acabar la unitat didàctica, els alumnes entregaran les rúbriques de coavaluació grupal $\mathrm{i}$, tot seguit, visualitzarem els vídeos que prèviament des de casa hauran penjat al canal de YouTube. Com ja els vam explicar a la primera 
sessió, cada grup haurà d'haver d'elaborat un vídeo breu en què s'exposin les conclusions que s'han extret a partir del treball de camp i que s'han reflectit per escrit a l'informe. Així mateix, hi poden incloure fragments de les entrevistes realitzades. Aquestes gravacions s'han de penjar al canal de YouTube que haurem creat ad hoc. Pensem que aquesta és una bona manera de posar en pràctica l'expressió oral i de motivar-los per dur a terme la tasca final. Probablement, si saben que s'han de gravar fent de youtubers, s'involucraran més en aquest projecte, atès que ens acostem més als seus interessos, donem cabuda a altres tipus d'habilitats i intel-ligències, i promocionem l'ús de les TIC amb finalitats didàctiques. Creiem que aquesta activitat pot ser un bon tancament de la seqüència didàctica, ja que tots els alumnes visualitzen el treball que han elaborat els seus companys d'una manera dinàmica i entretinguda.

\section{Conclusions}

A partir de diferents estudis, hem analitzat quina és la situació actual de l'educació lingüística i els hem utilitzat com a base per dissenyar una seqüència didàctica sobre sintaxi per a quart d'ESO. Aquesta revisió bibliogràfica ens ha fet reflexionar i ens ha confirmat la idea amb la qual encetàvem aquest article: hem d'atorgar un nou enfocament a l'estudi de la sintaxi dins els centres de secundària. Considerem que la proposta didàctica que hem elaborat és una mostra clara que és possible creure en un nou model de gramàtica, basat en la reflexió sobre la llengua i en l'aprofitament dels sabers gramaticals per al desenvolupament de les habilitats lingüístiques. Per aquest motiu, estem totalment d'acord amb l'afirmació realitzada per Cassany, Luna i Sanz (2009: 355):

l'ensenyament tradicional de la gramàtica per la gramàtica, com a fi en si mateixa, ha de deixar pas a un enfocament centrat en la millora de les capacitats comunicatives. Només té sentit disseccionar la frase, estudiar-la i aprendre conceptes teòrics si l'alumne és capaç de projectar aquests coneixements en la comprensió i la producció amb les quatre habilitats lingüístiques.

A més, a la nostra seqüència didàctica hem lligat el foment de cinc tipus d’intel-ligències múltiples amb una branca del coneixement lingüístic generalment poc donada a la innovació, com és la sintaxi. Són molts els psicòlegs i pedagogs que defensen els beneficis que reporta l'aplicació de la teoria de les 
intel-ligències múltiples a l'ensenyament, però, tot i això, només se'n parla de manera abstracta i existeixen pocs materials didàctics pràctics dissenyats per a secundària atenent els diferents tipus d'intel-ligències. De fet, els que hi ha són molt generals i tan sols ofereixen idees d'activitats que es poden realitzar a classe esporàdicament.

Així mateix, hem demostrat que la incorporació de la teoria de Gardner a l'educació, a part d'avenir-se amb el foment de les competències clau que estableix el currículum oficial, ofereix les eines necessàries per atendre la diversitat sense la necessitat d'etiquetar els alumnes. És a partir de les seves fortaleses que hem de treballar, per aconseguir engrescar-los i perquè el seu procés d'aprenentatge sigui el més beneficiós possible.

Finalment voldríem que la lectura d'aquest article encoratgés els docents a posar en pràctica aquesta proposta didàctica, i a dissenyar-ne d'altres en aquesta línia, ja que d'aquesta manera estaríem promovent i fent néixer en els alumnes l’interès per la naturalesa de quelcom tan seu com és la llengua.

\section{Bibliografia}

BosQUe, Ignacio i GALLEGO, Ángel J. (2016): "La aplicación de la gramática en el aula. Recursos didácticos clásicos y modernos para la enseñanza de la gramática”, Revista de Lingüística Teórica y Aplicada, 54 (2), pàgs. 63-83.

- (en premsa): "La gramática en la Enseñanza Media. Competencias oficiales y competencias necesarias", REGrOC, 1, pàgs. 1-55. Recuperat de: http://filcat.uab.cat/clt/membres/professors/d72a87 c296026810ba44 e7ac2e31f656560a94.pdf

CAMPS, Anna. (2000): “Aprendre gramàtica”, dins Camps, A. i Ferrer, M. (coord.). Gramàtica a l'aula, Barcelona: Graó, Biblioteca d'Articles, 123, pàgs. 101-118.

- (2006): "Seqüències didàctiques per aprendre gramàtica (SDG)", dins Camps, A. i Zayas, F. (eds.) Seqüències didàctiques per aprendre gramàtica, Barcelona: Graó, pàgs. 31-36.

CAMPS, Anna i Fontich, Xavier. (2006): "La construcció del coneixement gramatical dels alumnes de secundària a través de la recerca i el raonament: l'ús del pronom "hi" en el català oral", dins Camps, A. i Zayas, F. (eds.) Seqüències didàctiques per aprendre gramàtica, Barcelona: Graó, pàgs. 97-107.

CAMPS, Anna, Guasch, Oriol, Milian, Marta i Ribas, Teresa (coord.) (2005): Bases per a l'ensenyament de la gramàtica, Barcelona: Graó.

CAMPS, Anna i Zayas, Felipe. (2006): "Introducció", dins Camps, A. i Zayas, F. (eds.) Seqüències didàctiques per aprendre gramàtica, Barcelona: Graó, pàgs. 7-15. 
CASSANY, Daniel, Luna, Marta i Sanz, Glòria. (2009): Ensenyar llengua, 9a edició, Barcelona: Graó.

Decret de currículum = Decret 34/2015, de 15 de maig, pel qual s'estableix el currículum de l'educació secundària obligatòria a les Illes Balears, BOIB núm. $73 \S$ I, p. 25016 -25302 (2015).

GARDNER, Howard. (2001): Estructuras de la mente. La teoría de las inteligencias múltiples, Colombia: Fondo de cultura económica.

GRAU, Ramon. (2006): Aprenentatge basat en problemes. Recuperat de: http://www.xtec.cat/ rgrau/abp/abpbases.htm

JIMENO, Pedro. (2017): "Blogs i Twitter al servei de la reflexió gramatical", Articles de didàctica de la llengua $i$ de la literatura, 72, pàgs. 26-30.

LÓPEZ, Juan Carlos. (2014): "La taxonomía de Bloom y sus actualizaciones”. Recuperat de: http://eduteka.icesi.edu.co/articulos/TaxonomiaBloomCuadro

Olmos, Rafael. (2017): "Kahoot: iUn, dos, tres! Análisis de una aplicación de cuestionarios”, Íber: Didáctica de las Ciencias Sociales, Geografia e Historia, 86, pàgs. 51-56. 